\title{
Consecutive digital infrared thermography in patients with temporomandibular joint arthralgia
}

\author{
Cheul Kim ${ }^{1,2 \star}$ \\ ${ }^{1}$ Department of Oral Medicine and Diagnosis, College of Dentistry, Gangneung-Wonju National University, Gangneung, Korea \\ ${ }^{2}$ Research Institute of Oral Science, Gangneung-Wonju National University, Gangneung, Korea
}

The objective of this study was to investigate the changes of skin temperatures over the temporomandibular joint (TMJ) and clinical findings consecutively during conservative treatments in unilateral TMJ arthralgia patients. The study enrolled 31 patients with unilateral TMJ arthralgia and 26 healthy control subjects based on the Research Diagnostic Criteria for Temporomandibuar Disorders. The measurements of skin temperatures over the TMJ and clinical examinations were performed in all subjects at baseline, 2 and 4 weeks later, and patients were given conservative treatments. Thermographic examinations were performed before and after chewing activity for 5 minutes in each session. The data were analyzed by repeated-measures ANOVA. In affected TMJ, the change in temperature between before and after chewing activity was significantly high in TMJ arthralgia group and decreased after 2 and 4 weeks. Thermal asymmetry measured before chewing activity showed insignificant difference between groups. However, those measured after chewing activity were significantly high in TMJ arthralgia group and reduced to the similar level of control group after 2 and 4 weeks. After chewing activity, both skin temperature over painful TMJ and the extent of thermal asymmetry in TMJ arthralgia patients were higher than those of control group. These thermal indices of TMJ arthralgia patients were reduced in accordance with clinical improvements by conservative treatments. Consecutive thermography accompanying chewing activity which may increase TMJ pain temporarily can be a useful adjunctive technique to diagnose TMJ arthralgia and evaluate its clinical progression including level of pain.

Key Words: Arthralgia, Skin temperature, Temporomandibular joint, Thermography

(c) This is an open-access article distributed under the terms of the Creative Commons Attribution Non-Commercial License (http://creativecommons.org/licenses/by-nc/4.0) which permits unrestricted noncommercial use, distribution, and reproduction in any medium, provided the original work is properly cited.

\section{INTRODUCTION}

Temporomandibular disorder (TMD) represents a collective term including many clinical problems arisen from the masticatory musculature, temporomandibular joint (TMJ), and associated anatomic structures and is known to comprise a significant proportion of oral and facial pain along with odontogenic pain [1]. Pain is the one of the common causes TMD patients seek the medical help. Although the measurements of the visual analogue scale (VAS) and/or pressure pain threshold have been routinely used to evaluate pain of TMD patients in dental clinics, these can't exclude the possibility of interference by patient's own intention thoroughly. Furthermore, if the onset of patient's complaint

Received January 22, 2019; Revised February 12, 2019; Accepted February 13, 2019

Corresponding author: Cheul Kim, Department of Oral Medicine and Diagnosis, College of Dentistry, and Research Institute of Oral Science, Gangneung-Wonju National University, 7 Jukheon-gil, Gangneung 25457, Korea.

Tel: +82-33-640-3127, Fax: +82-33-640-3113, E-mail: chkim@gwnu.ac.kr

Copyright $\odot$ 2019, Oral Biology Research Institute 
is associated with bad events like an assault or traffic accident, they may be influenced by negative thoughts or the secondary gain such as litigation and financial rewards. The clinical evaluation including VAS and pain thresholds in these patients may not reflect the level of pain objectively. Therefore, it is thought that another diagnostic method is required to assess the functional and physiological rather than anatomical changes of painful site in TMD patients.

Digital infrared thermography (DIT) is one of the imaging techniques measuring skin temperatures. It has an excellent intra- and inter-rater reliability [2-5] and merits such as non-invasiveness, low costs, and absence of direct contact and exposure of ionizing radiation [6]. The thermography has been adopted extensively on early detection of breast cancer, diagnosing diabetic neuropathy, vascular disorders, and inflammatory skin diseases [7] as well as evaluation of the musculoskeletal disorders including shoulder impingement syndrome [8], whiplash injury [9], psoriatic arthritis [10], ligamentous injury of the knee [11], and low-back pain and sciatica [12].

There have also been many attempts to prove the diagnostic availability of DIT on TMD diagnostics. Some studies reported DIT could be a useful adjunctive technique to diagnose the TMD [13-16], whereas it was asserted that diagnostic validity was not outstanding despite its high reliability $[3,17,18]$. It may be assumed that the pathophysiologic heterogeneity in the TMD patient population and cross-sectional study design of previous studies were the part of possible causes for these conflicting results on the application of DIT in TMD diagnostics.

Therefore, this study was conducted to evaluate the usefulness of DIT for the evaluation of TMD patients. The aim of the present study was to investigate the changes of both skin temperatures over the TMJ and clinical findings consecutively during conservative treatments in unilateral TMJ arthralgia patients.

\section{MATERIALS AND METHODS}

\section{Subjects}

The study sample comprised 26 healthy volunteers (11 females and 15 males) aged 22 to 47 years (mean \pm stan- dard deviation [SD], $30.12 \pm 9.26$ years) with no subjective symptoms of TMD and 31 TMJ arthralgia patients (14 females and 17 males) aged 19 to 50 years (mean \pm SD, 32.81 \pm 18.13 years) who had unilateral TMJ involvement and met the Research Diagnostic Criteria for Temporomandibular Disorders (RDC/TMD) Group IIIa [19]; pain in one or both joint sites (lateral pole and/or posterior attachment) during palpation; one or more of the following selfreports of pain: pain in the region of the joint, pain in the joint during maximum unassisted opening, pain in the joint during assisted opening, and pain in the joint during lateral excursion; for a diagnosis of simple arthralgia, coarse crepitus must be absent. In addition, the patients with masticatory muscle disorders or TMJ disc displacements, and who showed degenerative bony changes of TMJ in radiographs were excluded. In control group, the left and right TMJ were assigned to affected and unaffected side, respectively, to evaluate thermal asymmetry, because the control subjects didn't have TMJ pain. The exclusion criteria for both groups were as follows: younger than 18 and older than 50 years, body mass index over $25 \mathrm{~kg} / \mathrm{m}^{2}$, under any other oral and facial pain or systemic diseases and taking analgesics and vasoactive drugs.

This research was approved from the Institutional Review Board (IRB) of Gangneung-Wonju National University Dental Hospital in Gangneung, Korea (IRB no. 2015-015). All subjects were informed about the aim and method of present study and agreed to participate voluntarily by signing an informed consent.

\section{Digital infrared thermography}

The examination room was maintained at controlled temperature of $22^{\circ} \mathrm{C}$ to $25^{\circ} \mathrm{C}$ and relative humidity of $40 \%$ to $60 \%$. It was illuminated by a fluorescent ceiling light without any heat-generating equipment and windows.

All subjects were seated in an examination chair with comfortable position and remained the examination room at least for 10 minutes to acclimate the room temperature prior to test. The subjects were asked to pin up their hair when necessary, and relax their facial muscles, keeping their teeth apart to prevent from clenching. An orofacial pain specialist localized skin surfaces over the both TMJs 
by careful palpation during mouth opening and then attached circular polystyrene marker with $1.5 \mathrm{~cm}$ diameter which had an insulating characteristic. Two lateral thermograms from both sides of face were taken at a distance of $100 \mathrm{~cm}$ and a constant angle of $90^{\circ}$ between the infrared camera and the patient's lateral aspect by using T-1000 digital infrared thermography system (MESH, Wonju, Korea) measuring skin temperatures with a resolution accuracy of $0.025^{\circ} \mathrm{C}$. For the analysis of thermal asymmetry, the difference of temperatures $(\Delta \mathrm{T})$ calculated by subtracting temperatures of intact side from those of affected side of TMJ was taken. The Fig. 1 shows that the setting for thermographic imaging in the examination room without the presence of heat-generating equipment or the incidence of direct air or sunlight in (A) and an example of thermogram in (B).

\section{Protocol}

In all subjects, thermographic examination of TMJ and clinical examinations including VAS, TMJ palpation, and range of mouth opening without pain were performed by a single orofacial pain specialist at first visit (baseline), 2 and 4 weeks later. Thermographic examination was repeated before and after $5 \mathrm{~g}$ of gum chewing $(20 \times 74 \times 1 \mathrm{~mm}$; Lotte, Seoul, Korea) for 5 minutes with ipsilateral posterior teeth of affected side which increased TMJ pain temporarily in each session.

The TMJ arthralgia patients were given conservative treatments including analgesics and anti-inflammatory medications, physical therapies, and behavioral therapies for 4 weeks to relieve their symptoms. On the other hand, the healthy controls were given same examinations without any treatments at the same sessions.

All obtained data were analyzed by repeated measures analyses of variance using SPSS 23 (IBM Corp., Armonk, NY, USA), with $p$-values less than 0.05 considered to be statistically significant in each test.

\section{RESULTS}

The Table 1 shows the changes of clinical findings in both groups during 4 weeks. At baseline, VAS and TMJ palpation score were higher in TMJ arthralgia group. In the ensuing weeks, these were decreased toward the lower level through the conservative treatments. The range of mouth opening without pain was lower in TMJ arthralgia group and improved significantly over time, too. These are suggested by the raw data (Table 1). Table 2 demonstrates the raw data of skin temperatures over the TMJ which measured before and after chewing activity. Table 3 displays the comparison of delta temperatures measured before and after chewing activity in both sides of TMJ.

The statistically significant interactions of variables between session and group are shown in Table 4.

In Fig. 2, the delta temperatures between before and after chewing activity were higher in affected TMJ of TMJ arthralgia group and decreased to the lower level at 2 and
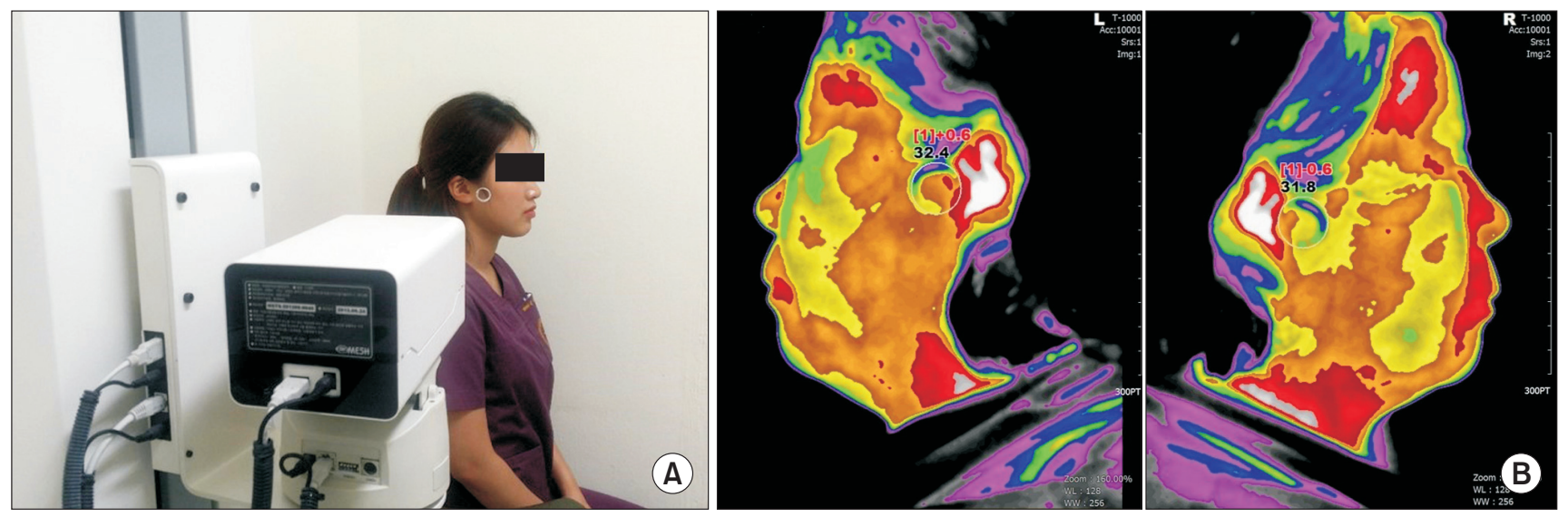

Fig. 1. Setting for thermographic imaging in the examination room (A) and thermograms of a subject's face (B). 
Table 1. Changes of VAS, TMJ palpation score, and the range of mouth opening without pain in healthy control and TMJ arthralgia patients

\begin{tabular}{|c|c|c|c|c|c|c|}
\hline \multirow[b]{2}{*}{ Session } & \multicolumn{2}{|c|}{ VAS (0-100) } & \multicolumn{2}{|c|}{ TMJ palpation score $(0-3)$} & \multicolumn{2}{|c|}{ Mouth opening (mm) } \\
\hline & $\begin{array}{c}\text { Control } \\
(n=26)\end{array}$ & $\begin{array}{c}\text { Arthralgia } \\
\qquad(n=31)\end{array}$ & $\begin{array}{c}\text { Control } \\
(n=26)\end{array}$ & $\begin{array}{c}\text { Arthralgia } \\
\qquad(n=31)\end{array}$ & $\begin{array}{c}\text { Control } \\
(n=26)\end{array}$ & $\begin{array}{c}\text { Arthralgia } \\
(\mathbf{n}=31)\end{array}$ \\
\hline Baseline & $0.62 \pm 1.24$ & $59.65 \pm 17.17$ & $0.19 \pm 0.41$ & $2.00 \pm 0.73$ & $49.08 \pm 3.69$ & $39.42 \pm 8.73$ \\
\hline 2 weeks & $0.62 \pm 1.17$ & $28.26 \pm 17.51$ & $0.19 \pm 0.40$ & $1.26 \pm 0.73$ & $49.00 \pm 3.67$ & $44.39 \pm 8.39$ \\
\hline 4 weeks & $0.46 \pm 1.10$ & $16.68 \pm 17.87$ & $0.12 \pm 0.33$ & $0.97 \pm 0.75$ & $49.15 \pm 3.65$ & $47.29 \pm 5.99$ \\
\hline
\end{tabular}

Values are presented as mean \pm standard deviation.

VAS, visual analogue scale; TMJ, temporomandibular joint.

Table 2. Skin temperatures over the TMJ measured before and after chewing activity in healthy control and TMJ arthralgia patients $\left({ }^{\circ} \mathrm{C}\right)$

\begin{tabular}{|c|c|c|c|c|c|c|c|c|}
\hline \multirow{3}{*}{ Session } & \multicolumn{4}{|c|}{ Affected side } & \multicolumn{4}{|c|}{ Unaffected side } \\
\hline & \multicolumn{2}{|c|}{ Before chewing activity } & \multicolumn{2}{|c|}{ After chewing activity } & \multicolumn{2}{|c|}{ Before chewing activity } & \multicolumn{2}{|c|}{ After chewing activity } \\
\hline & $\begin{array}{c}\text { Control } \\
(n=26)\end{array}$ & $\begin{array}{l}\text { Arthralgia } \\
\qquad(\mathrm{n}=31)\end{array}$ & $\begin{array}{c}\text { Control } \\
(n=26)\end{array}$ & $\begin{array}{l}\text { Arthralgia } \\
\qquad(\mathrm{n}=31)\end{array}$ & $\begin{array}{c}\text { Control } \\
(n=26)\end{array}$ & $\begin{array}{l}\text { Arthralgia } \\
\qquad(\mathrm{n}=31)\end{array}$ & $\begin{array}{c}\text { Control } \\
(n=26)\end{array}$ & $\begin{array}{l}\text { Arthralgia } \\
\qquad(\mathrm{n}=\mathbf{3 1})\end{array}$ \\
\hline Baseline & $32.32 \pm 1.02$ & $32.78 \pm 1.06$ & $32.35 \pm 1.05$ & $33.24 \pm 1.09$ & $32.27 \pm 0.94$ & $32.65 \pm 0.95$ & $32.32 \pm 1.02$ & $32.72 \pm 0.90$ \\
\hline 2 weeks & $32.37 \pm 0.98$ & $32.60 \pm 1.37$ & $32.30 \pm 1.02$ & $32.85 \pm 1.31$ & $32.38 \pm 0.93$ & $32.64 \pm 1.36$ & $32.53 \pm 0.94$ & $32.66 \pm 1.30$ \\
\hline 4 weeks & $32.26 \pm 0.90$ & $32.62 \pm 1.35$ & $32.41 \pm 0.96$ & $32.77 \pm 1.36$ & $32.30 \pm 0.95$ & $32.61 \pm 1.33$ & $32.43 \pm 0.93$ & $32.71 \pm 1.35$ \\
\hline
\end{tabular}

Values are presented as mean \pm standard deviation.

In control group, the affected side and unaffected side are the left and right TMJs, respectively. Chewing activity was performed by gum chewing for 5 minutes.

TMJ, temporomandibular joint.

Table 3. The delta temperatures $(\Delta \mathrm{T})$ measured before and after chewing activity in both sides of $\mathrm{TMJ}\left({ }^{\circ} \mathrm{C}\right)$

\begin{tabular}{|c|c|c|c|c|c|c|c|c|}
\hline \multirow{3}{*}{ Session } & \multicolumn{4}{|c|}{$\Delta \mathrm{T}$ between before and after chewing activity } & \multicolumn{4}{|c|}{$\Delta \mathrm{T}$ between both sides of TMJ } \\
\hline & \multicolumn{2}{|c|}{ Affected side } & \multicolumn{2}{|c|}{ Unaffected side } & \multicolumn{2}{|c|}{ Before chewing activity } & \multicolumn{2}{|c|}{ After chewing activity } \\
\hline & $\begin{array}{c}\text { Control } \\
(n=26)\end{array}$ & $\begin{array}{l}\text { Arthralgia } \\
\qquad(n=31)\end{array}$ & $\begin{array}{c}\text { Control } \\
(n=26)\end{array}$ & $\begin{array}{l}\text { Arthralgia } \\
\qquad(n=31)\end{array}$ & $\begin{array}{c}\text { Control } \\
(n=26)\end{array}$ & $\begin{array}{l}\text { Arthralgia } \\
\qquad(n=31)\end{array}$ & $\begin{array}{c}\text { Control } \\
(n=26)\end{array}$ & $\begin{array}{l}\text { Arthralgia } \\
\qquad(\mathrm{n}=31)\end{array}$ \\
\hline Baseline & $0.03 \pm 0.20$ & $0.46 \pm 0.25$ & $0.04 \pm 0.14$ & $0.07 \pm 0.11$ & $0.05 \pm 0.16$ & $0.13 \pm 0.28$ & $0.03 \pm 0.26$ & $0.52 \pm 0.43$ \\
\hline 2 weeks & $-0.07 \pm 0.41$ & $0.25 \pm 0.45$ & $0.15 \pm 0.35$ & $0.02 \pm 0.23$ & $-0.01 \pm 0.31$ & $-0.05 \pm 0.30$ & $-0.24 \pm 0.43$ & $0.19 \pm 0.40$ \\
\hline 4 weeks & $0.15 \pm 0.35$ & $0.15 \pm 0.17$ & $0.13 \pm 0.24$ & $0.10 \pm 0.18$ & $-0.04 \pm 0.21$ & $0.01 \pm 0.26$ & $-0.02 \pm 0.24$ & $0.06 \pm 0.26$ \\
\hline
\end{tabular}

Values are presented as mean \pm standard deviation.

Chewing activity was performed by gum chewing for 5 minutes.

$\Delta \mathrm{T}$, the difference of temperatures; TMJ, temporomandibular joint.

4 weeks later. This decrease in TMJ arthralgia group is shown by the statistically significant interaction between group and session $(p=0.002)$. But, delta temperatures of unaffected TMJ did not significantly differ between groups or among sessions regardless of chewing activity, and there was not a statistically significant interaction between group and session ( $p=0.141)$. In Fig. 3, we can see the delta temperatures between both sides of TMJ, namely the extent of thermal asymmetry. The delta temperatures between both sides of TMJ which measured before chewing activity did not differ significantly between groups $(p=0.439)$. But those measured after chewing activity were higher in TMJ arthralgia group and reduced to the similar level of control group at 2 and 4 weeks later showing significant interaction between group and session ( $p=0.001$ ) 
Table 4. Statistical results of repeated measures analyses of variance ( $p$-values)

\begin{tabular}{|c|c|c|c|}
\hline \multirow{2}{*}{ Dependent variable } & \multicolumn{3}{|c|}{ Independent variable } \\
\hline & Session $\times$ Group & Session & Group \\
\hline Visual analogue scale & $0.000^{\mathrm{a}}$ & 0.000 & 0.000 \\
\hline TMJ palpation score & $0.000^{\mathrm{b}}$ & 0.000 & 0.000 \\
\hline Range of mouth opening without pain & $0.000^{c}$ & 0.000 & 0.001 \\
\hline$\Delta \mathrm{T}$ between both sides before chewing activity & 0.439 & 0.015 & 0.496 \\
\hline$\Delta \mathrm{T}$ between both sides after chewing activity & $0.001^{\mathrm{d}}$ & 0.000 & 0.000 \\
\hline$\Delta \mathrm{T}$ between before and after chewing activity in affected side & $0.002^{\mathrm{e}}$ & 0.039 & 0.000 \\
\hline$\Delta \mathrm{T}$ between before and after chewing activity in unaffected side & 0.141 & 0.361 & 0.179 \\
\hline
\end{tabular}

Session: baseline, 2 and 4 weeks later, Group: control and TMJ arthralgia.

$\mathrm{TMJ}$, temporomandibular joint; $\Delta \mathrm{T}$, the difference of temperatures.

Helmert contrasts for baseline vs. later and 2 weeks vs. 4 weeks: ${ }^{\mathrm{a}} p=0.008, p=0.002 ;{ }^{\mathrm{b}} p=0.041, p=0.053 ;{ }^{\mathrm{c}} p=0.003, p=0.047 ;{ }^{\mathrm{d}} p=0.000, p=0.096$; ${ }^{\mathrm{e}} \mathrm{p}=0.007, p=0.035$.
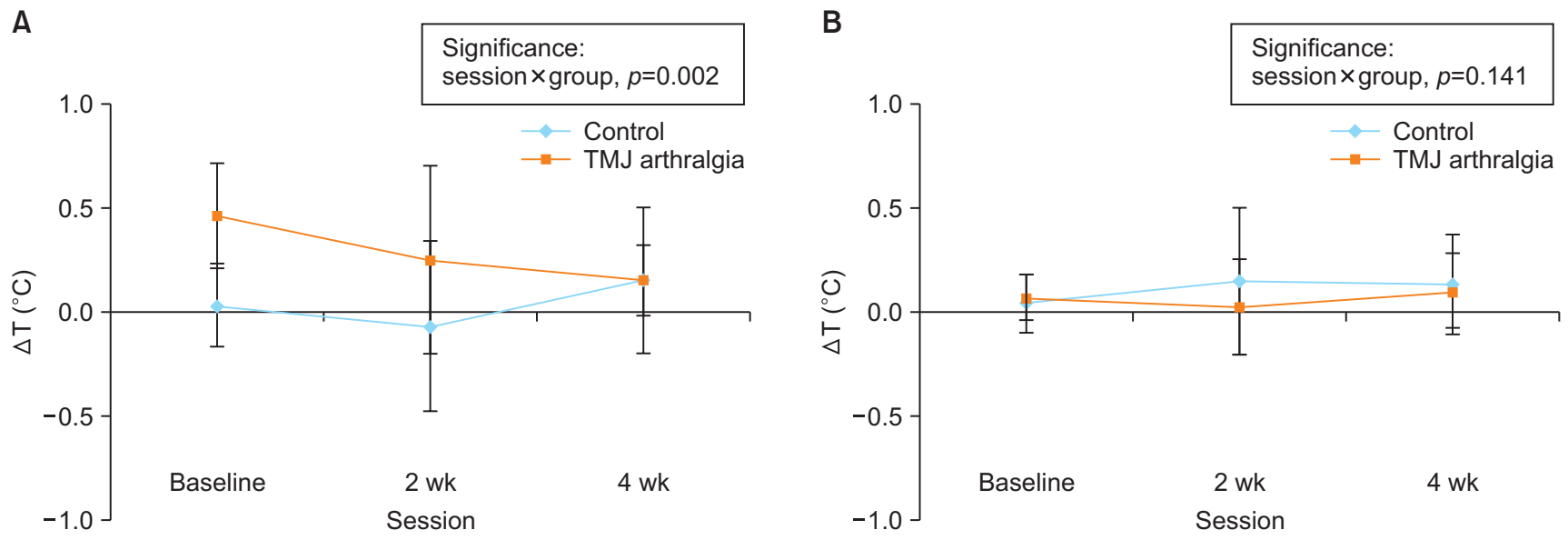

Fig. 2. The difference of skin temperatures $(\Delta \mathrm{T})$ over the TMJ between before and after chewing activity in affected $(\mathrm{A})$ and unaffected side $(\mathrm{B})$. TMJ, temporomandibular joint.
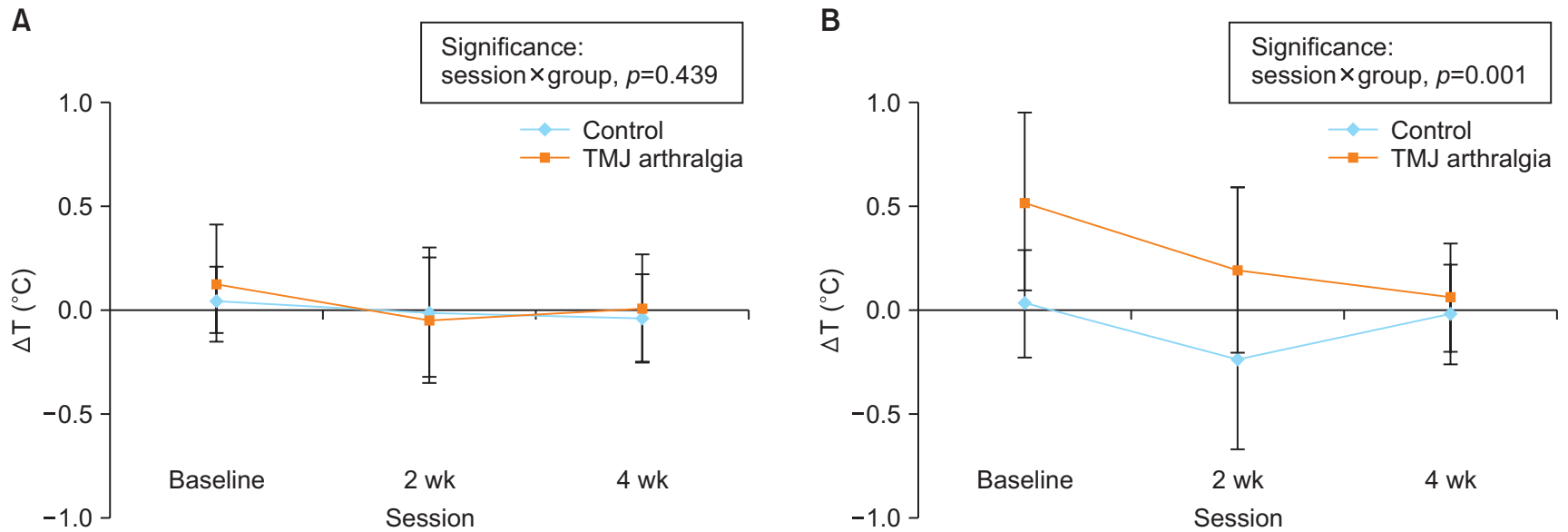

Fig. 3. The difference of skin temperatures $(\Delta \mathrm{T})$ between both sides of TMJ measured before $(\mathrm{A})$ and after chewing activity (B). 


\section{DISCUSSION}

Our main finding was that after the chewing activity inducing temporary increase of TMJ pain, both skin temperatures over painful TMJ and the delta temperatures between both sides of TMJ in TMJ arthralgia patients were higher than those of healthy controls at baseline, while these thermal indices measured prior to chewing activity were not different significantly with those of healthy controls. In addition, as the conservative treatments were applied to the TMJ arthralgia patients, these thermal indices were reduced in accordance with clinical improvements.

These results are consistent with the previous report emphasizing joint loading activity like a gum chewing help to increase the diagnostic efficiency of thermography in identifying TMD patients [6]. Although there was a slight increase of skin temperatures in unaffected side of TMJ after the chewing activity, a statistically significant change was found in only affected side of TMJ in patient group.

This finding, no significant change of skin temperature after chewing activity in non-painful TMJ, does not correspond with the result obtained by Morimoto et al. [20] which showed gum chewing produced significant increase of skin temperature than did the unloaded jaw movements in masticatory muscles of healthy adults. In the present study, there were no significant changes of skin temperatures before and after gum chewing activity in unaffected TMJ of arthralgia patients and both sides of TMJ of healthy controls. It can be thought that this output gap is originated from the difference of the region of interest (ROI) for temperature measurement. Because TMJ region has a relatively smaller amount of vascularity compared to the masticatory muscles, the measurement of the skin temperature over sound TMJ may not be affected significantly by chewing activity as masticatory muscles which have sufficient increase of blood supply during loaded jaw movements. Namely, loaded jaw activity like a gum chewing can be assumed to have a significant effect on thermal change in painful TMJ without any influence on sound TMJ. We could confirm the importance of loaded jaw activity prior to DIT as a critical factor to discriminate painful joint from sound one by increasing the skin temperature over the TMJ.

In the pilot study, common chief complaint of most TMJ arthralgia patients was preauricular pain during mandibular movement, particularly mastication and mouth opening, and they complained unbearable preauricular pain when they chewed gum over about 5 minutes. Therefore, we used gum chewing activity for 5-minutes to elicit increase of TMJ pain temporarily.

DIT is a non-invasive and economical assessment tool which allows to measure skin temperatures over the ROI without patient's discomfort by infrared detection from the human body surface. This is known to provide information about normal and abnormal functioning of the sensory and sympathetic nervous systems, vascular dysfunction, and local inflammatory reactions [21], and therefore, it may represent physiological changes rather than anatomic changes of ROI quantitatively [22]. Although normal body temperatures are not constant over the course of a day and may vary between persons, the normal thermogram has been known to demonstrate thermal symmetry when comparing corresponding sides of the body in healthy subjects [13].

DIT has also been applied to evaluation of TMD patients $[23,24]$, however, its diagnostic value and usefulness are not consistent according to both the region of temperature measurements and subject population like myogenous or arthrogenous [3,6,13,17,18,24]. TMD can affect other anatomic structures of the masticatory system simultaneously and many arthrogenous TMD patients often accompany masticatory muscle pain, therefore, this comorbidity and heterogeneity of study population may be thought to affect and bias the analyses of thermal characteristics of each patient population. Furthermore, bilateral or unilateral involvement of TMJ which may also affect thermal asymmetry was not mentioned either in several previous studies $[3,17,18]$. Therefore, the present study was designed to evaluate its diagnostic usefulness within only unilateral TMJ arthralgia patients.

In general, the evaluation of arthrogenous TMD patients are dependent upon diagnostic imaging examinations like plain radiographs, computed tomography, and magnetic resonance imaging as well as clinical examinations, because many of them are arisen from disorders of variable anatomic TMJ substructures, for example, articular disc, ligaments, synovial capsule, and bone tissue. In some cases of TMJ arthralgia without accompanying the disorder of 
disc or bony structures of TMJ, namely in case of synovitis and retrodiscitis, the evaluation of patients, particularly level of pain, is mainly determined by clinical assessments including medical examination by interview, TMJ palpation test and/or the verbal expression by patients themselves like a VAS.

However, these clinical examinations have the limitations which depend upon the statements or responses of patients themselves, and most of diagnostic imaging techniques can't play a major role in arthralgia patient who does not accompany deformation of TMJ anatomic structures. Therefore, there have been some efforts to employ DIT as another evaluation tool which can reflect the intensity of pain $[9,25]$ independent of patient's response as well as diagnosis of disease $[8,10-12]$ in musculoskeletal disorders.

DIT findings can be graded and quantified; therefore, it can be effective in assessing improvement of patient's symptom following treatments of disease if the thermal changes of ROI reflect the clinical progressions. Neuropathic or musculoskeletal pain itself does not change skin temperature directly. However, it may be thought that inflammatory reaction causing pain or disorder of autonomic nervous system influencing body temperature may change skin temperature indirectly.

On the other hand, quantitative analysis of thermal emission profiles was conducted in animal models of experimental neuropathic pain and inflammatory arthritis [26,27]. Bennett and Ochoa [26] reported that abnormal deviations of skin temperature were obtained from hind paws of rats on the sciatic nerve-injured side and became normal after the damaged sciatic nerve was transected. The significant correlations between thermal imaging changes and severity of arthritis were demonstrated in a model of localized inflammatory arthritis of the rat ankle; therefore, thermography appeared to be helpful in evaluating progression of inflammatory arthritis [27]. It could be differentiated mild peripheral nerve injury from moderate-to-severe injuries in rat through the thermography as well [28].

In conclusion, although DIT may not be suitable for the diagnostic method of the specific musculoskeletal disorders, consecutive DIT accompanying chewing activity which may increase TMJ pain temporarily was shown to be a useful adjunctive technique to diagnose TMJ arthralgia and evaluate its clinical progression objectively including level of pain through the present study.

This study has a limitation that should be addressed. The TMJ arthralgia patients who did not take treatments should be enrolled as a control group, however, it was not possible for them to withstand their pain without any treatment for 4 weeks in clinical situation.

\section{ACKNOWLEDGEMENTS}

This study was supported by 2015 Academic Research Support Program in Gangneung-Wonju National University. The author would like to thank Dr. Sun-Mee Bae for collecting the data.

\section{CONFLICTS OF INTEREST}

The author declares that he has no competing interests.

\section{ORCID}

\author{
Cheul Kim \\ https://orcid.org/0000-0001-7935-3244
}

\section{REFERENCES}

1. McNeill C, Mohl ND, Rugh JD, Tanaka TT. Temporomandibular disorders: diagnosis, management, education, and research. J Am Dent Assoc 1990;120:253, 255, 257 passim. doi: 10.14219/jada.archive.1990.0049.

2. Costa AC, Dibai Filho AV, Packer AC, Rodrigues-Bigaton D. Intra and inter-rater reliability of infrared image analysis of masticatory and upper trapezius muscles in women with and without temporomandibular disorder. Braz J Phys Ther 2013;17:24-31. doi: 10.1590/S1413-35552012005000058.

3. Rodrigues-Bigaton D, Dibai Filho AV, Costa AC, Packer AC, de Castro EM. Accuracy and reliability of infrared thermography in the diagnosis of arthralgia in women with temporomandibular disorder. J Manipulative Physiol Ther 2013;36:253-258. doi: 10.1016/j.jmpt.2013.04.006.

4. McCoy M, Campbell I, Stone P, Fedorchuk C, Wijayawardana S, Easley K. Intra-examiner and inter-examiner reproducibility of paraspinal thermography. PLoS One 2011;6:e16535. doi: 10.1371/journal.pone.0016535.

5. Owens EF Jr, Hart JF, Donofrio JJ, Haralambous J, Mi- 
erzejewski E. Paraspinal skin temperature patterns: an interexaminer and intraexaminer reliability study. J Manipulative Physiol Ther 2004;27:155-159. doi: 10.1016/ j.jmpt.2003.12.019.

6. Woźniak K, Szyszka-Sommerfeld L, Trybek G, Piątkowska D. Assessment of the sensitivity, specificity, and accuracy of thermography in identifying patients with TMD. Med Sci Monit 2015;21:1485-1493. doi: 10.12659/MSM.893863.

7. Lahiri B, Bagavathiappan S, Jayakumar T, Philip J. Medical applications of infrared thermography: a review. Infrared Phys Tech 2012;55:221-235. doi: 10.1016/j.infrared. 2012.03.007.

8. Park JY, Hyun JK, Seo JB. The effectiveness of digital infrared thermographic imaging in patients with shoulder impingement syndrome. J Shoulder Elbow Surg 2007;16:548554. doi: 10.1016/j.jse.2006.11.010.

9. Lee YS, Paeng SH, Farhadi HF, Lee WH, Kim ST, Lee KS. The effectiveness of infrared thermography in patients with whiplash injury. J Korean Neurosurg Soc 2015;57:283-288. doi: 10.3340/jkns.2015.57.4.283.

10. Capo A, Ismail E, Cardone D, Celletti E, Auriemma M, Sabatini E, Merla A, Amerio P. Joint functional impairment and thermal alterations in patients with psoriatic arthritis: a thermal imaging study. Microvasc Res 2015;102:86-91. doi: 10.1016/j.mvr.2015.08.008.

11. Yang H, Park H, Lim C, Park S, Lee K. Infrared thermal imaging in patients with medial collateral ligament injury of the knee-a retrospective study. J Pharmacopuncture 2014;17:50-54. doi: 10.3831/KPI.2014.17.036.

12. Uematsu S, Jankel WR, Edwin DH, Kim W, Kozikowski J, Rosenbaum A, Long DM. Quantification of thermal asymmetry. Part 2: application in low-back pain and sciatica. J Neurosurg 1988;69:556-561. doi: 10.3171/jns. 1988.69.4.0556.

13. Canavan D, Gratt BM. Electronic thermography for the assessment of mild and moderate temporomandibular joint dysfunction. Oral Surg Oral Med Oral Pathol Oral Radiol Endod 1995;79:778-786. doi: 10.1016/S1079-2104 (05)80316-6.

14. Dibai-Filho AV, Packer AC, Costa AC, Rodrigues-Bigaton D. The chronicity of myogenous temporomandibular disorder changes the skin temperature over the anterior temporalis muscle. J Bodyw Mov Ther 2014;18:430-434. doi: 10.1016/ j.jbmt.2013.11.001.

15. Barão VA, Gallo AK, Zuim PR, Garcia AR, Assunção WG. Effect of occlusal splint treatment on the temperature of different muscles in patients with TMD. J Prosthodont Res 2011;55:19-23. doi: 10.1016/j.jpor.2010.06.001.

16. Gratt BM, Sickles EA, Wexler CE. Thermographic characterization of osteoarthrosis of the temporomandibular joint. J Orofac Pain 1993;7:345-353.

17. Dibai Filho AV, Packer AC, Costa AC, Rodrigues-Bigaton
D. Accuracy of infrared thermography of the masticatory muscles for the diagnosis of myogenous temporomandibular disorder. J Manipulative Physiol Ther 2013;36:245-252. doi: 10.1016/j.jmpt.2013.04.007.

18. Dibai-Filho AV, Costa AC, Packer AC, Rodrigues-Bigaton D. Correlation between skin surface temperature over masticatory muscles and pain intensity in women with myogenous temporomandibular disorder. J Back Musculoskelet Rehabil 2013;26:323-328. doi: 10.3233/BMR-130387.

19. Dworkin SF, LeResche L. Research diagnostic criteria for temporomandibular disorders: review, criteria, examinations and specifications, critique. J Craniomandib Disord 1992;6:301-355.

20. Morimoto T, Takada K, Hijiya H, Yasuda Y, Sakuda M. Changes in facial skin temperature associated with chewing efforts in man: a thermographic evaluation. Arch Oral Biol 1991;36:665-670. doi: 10.1016/0003-9969(91)90019Q.

21. Childs C. Body temperature and clinical thermometry. Handb Clin Neurol 2018;157:467-482. doi: 10.1016/B9780-444-64074-1.00029-X.

22. Fikackova H, Ekberg E. Can infrared thermography be a diagnostic tool for arthralgia of the temporomandibular joint? Oral Surg Oral Med Oral Pathol Oral Radiol Endod 2004;98:643-650. doi: 10.1016/j.tripleo.2004.02.080.

23. Dibai-Filho AV, Costa AC, Packer AC, de Castro EM, Rodrigues-Bigaton D. Women with more severe degrees of temporomandibular disorder exhibit an increase in temperature over the temporomandibular joint. Saudi Dent J 2015;27:44-49. doi: 10.1016/j.sdenti.2014.10.002.

24. Haddad DS, Brioschi ML, Vardasca R, Weber M, Crosato EM, Arita ES. Thermographic characterization of masticatory muscle regions in volunteers with and without myogenous temporomandibular disorder: preliminary results. Dentomaxillofac Radiol 2014;43:20130440. doi: 10.1259/ dmfr.20130440.

25. Frize M, Ogungbemile A. Estimating rheumatoid arthritis activity with infrared image analysis. Stud Health Technol Inform 2012;180:594-598. doi: 10.3233/978-1-61499101-4-594.

26. Bennett GJ, Ochoa JL. Thermographic observations on rats with experimental neuropathic pain. Pain 1991;45:61-67. doi: 10.1016/0304-3959(91)90165-T.

27. Brenner M, Braun C, Oster M, Gulko PS. Thermal signature analysis as a novel method for evaluating inflammatory arthritis activity. Ann Rheum Dis 2006;65:306-311. doi: 10.1136/ard.2004.035246.

28. Kim MS, Seo DH, Lim MH, Kim TU, Lee SJ, Hyun JK. Skin temperature changes following sciatic nerve injury in rats. J Neurotrauma 2012;29:2738-2747. doi: 10.1089/ neu.2012.2414. 